\title{
BIOÉTICA APLICADA À ASSISTÊNCIA DE ENFERMAGEM'
}

\author{
APLICATED BIOETHIC TO THE NURSING ASSISTANCE \\ BIOÉTICA APLICADA A LA ASISTENCIA DE ENFERMERÍA
}

Valéria Lerch Lunardi2

RESUMO: A partir do conceito de governabilidade de Foucault como um tema ligado à ética, ao exercício da liberdade e da autonomia, discute o enfrentamento de situações de conflito ético, presentes no cotidiano da enfermagem, e em especial da enfermagem nefrológica. Defende a necessidade da enfermeira, na sua prática, optar por advogar a favor dos direitos do cliente.

PALAVRAS CHAVE: governabilidade, bioética, conflito ético, transplante

ABSTRACT: From the Foucault governability concept as a theme articulated to the concepts of authonomy, freedom and ethic, in this text, the author discusses the ethic conflict situations confrontation, which are presents in the nursing quotidian and specially in the nefrology nursing. The author defends the need of the nurse, in her practice, to decide to advocate in favor of the client rights

KEY WORDS: governability, bioethic, ethic conflict, transplant

RESUMEN: A partir del concepto de gobernabilidad de Foucault como un tema ligado a la ética, al ejercicio de la liberdad y de la autonomía, se discute el enfrentamiento de situaciones de conflicto ético presentes en el cotidiano de la enfermería y en especial de la enfermería nefrologica. Se defiende la necesidad de que la enfermera en su práctica, opte por abogar en favor de los derechos de los clientes.

PALABRAS CLAVE: gobernabilidad, bioética, conflicto ético, transplante

Falar em bioética como uma parte da ética, significa focalizar questões que se referem à vida humana. De acordo com a Encyclopedia of Bioethics, bioética pode ser conceituada como "o estudo sistemático do comportamento humano na área das ciências da vida e dos cuidados da saúde, quando se examina esse comportamento à luz dos valores e dos princípios morais". (Bellino, 1997, p.21). Então, a bioética se preocupa com as questões referentes à vida humana, desde o seu início até o seu final, à pesquisa com seres humanos, à engenharia genética, métodos de fecundação, transplante de órgãos, manutenção da vida, pacientes terminais, dentre outros temas.

Neste sentido, falar em bioética pode significar falar do nosso cotidiano profissional, das relações que estabelecemos com nossos colegas, com nossos clientes, com a instituição empregadora, quando este relacionamento torna-se objeto do nosso pensamento reflexivo, indagador, problematizador.

${ }^{1}$ Conferência apresentada no IX Congresso Brasileiro de Enfermagem em Nefrologia, Porto Alegre, 1998.

2 Mestre em Educação/UFRGS. Doutoria em Enfermagem/UFSC. Professora Adjunto do Departamento de Enfermagem da FL'ndação Universidade do Rio Grande - FURG/RS. Membro do Núcleo de Estudos e Pesquuisas em Saúde - NEPES FURG.

R. Bras. Enferm. Brasília, v. 51, ’ . 4, p. 655-664 out./dez. 1998 
Por outro lado, mesmo que não tenhamos consciência, estamos, continuamente, tomando decisões morais, como ao priorizarmos o nosso fazer, o uso qualitativo do nosso tempo, ao delegarmos tarefas a diferentes membros da nossa equipe, ao selecionarmos e/ou aceitarmos determinados materiais para assistir nossos clientes, ao prescrevermos cuidados, ao nos relacionarmos com os outros, clientes, familiares, profissionais, a instituição de saúde como um todo.

A palavra moral, então, pode ser compreendida como um código moral, decorrente de um sistema de valores, ou seja, "um conjunto de valores e regras de ação propostos aos indivíduos e aos grupos por intermédio de aparelhos diversos". (Foucault, 1984, p. 26). No entanto, há as normas de comportamento e os modos pelos quais os indivíduos decidem conduzir-se e constituir-se a si mesmos como sujeitos morais das suas ações frente aos códigos prescritivos e as normas morais, de modo a que não atuem apenas como agentes e objetos, mas como sujeitos morais do seu agir. Para ser sujeito moral das nossas ações, não é compatível apenas obedecer a uma moral imposta, o que, muitas vezes, é realizado de um modo automático, mecânico e, quem sabe, rotineiro; para ser sujeito moral nas relações com o outro, é preciso ser um sujeito autônomo e agir, voluntariamente, frente a certos valores. É preciso pensar, decidir, refletir e questionar o nosso fazer, a nossa situação no mundo, enfim, é preciso problematizar as nossas práticas e perguntarnos se o que é, o que existe e se o que se faz, necessariamente, deve continuar acontecendo e se fazendo deste modo.

Para se falar em ética, é preciso que reservemos e priorizemos um espaço de tempo das nossas vidas para (re)vermos e (re)pensarmos o nosso cotidiano pessoal e profissional e nos perguntarmos o que devemos fazer, como devemos agir, porque agimos assim, se o que fazemos é o que devemos continuar fazendo e, fundamentalmente, quem tem se beneficiado com o nosso fazer, com a nossa prática, com o nosso modo de ser. É importante acrescentar que nós não nascemos éticos, nossa estruturação ética vai se dando com o nosso próprio desenvolvimento (Cohen; Segre, 1995).

Neste texto, então, pretendo pontuar algumas questões referentes ao governo de si e ao governo dos outros (Foucault, 1990) no exercício da enfermagem e em especial, no exercício da enfermagem nefrológica, entendendo a governabilidade como um tema diretamente ligado à ética, já que se refere, permanentemente, à possibilidade de sermos ou não sujeitos morais das nossas ações, de favorecermos ou dificultarmos que os outros, também, sejam sujeitos morais das suas ações. Em nossa prática profissional, quando nos propomos a reconhecer-nos como sujeitos morais das nossas ações, refletindo o nosso fazer, questionando a nossa atuação, duvidando, talvez, das nossas certezas e da justificativa moral de algumas peculiaridades do nosso fazer, podem ser muitos os conflitos ou dilemas éticos, em que dois valores morais podem encontrar-se em conflito, de modo que cada um deles pode ser respeitado somente às custas do outro. (Luna; Salles, 1995). Neste sentido, poderia dizer que somos livres para mantermos ou não os clientes que assistimos e que se encontram em estado de ignorância e de desconhecimento em relação aos seus direitos, podendo advogar contra ou a seu favor, contra ou a favor dos seus direitos, contra ou a favor da sua possibilidade de ser sujeito, ou de ser mais 
sujeito ou, predominantemente, objeto da sua vida e da sua saúde.

No nosso dia a dia profissional, podem ser muitas as vivências em que o cliente não tem sua condição de pessoa reconhecida, já que a ele não é dado o direito, muitas vezes, de decidir, de optar, de consentir ou recusar um tratamento entendido pela equipe médica e/ou de saúde como o melhor tratamento. É possível que, em algumas situações, seja respeitado e buscado o consentimento livre e esclarecido, em que, numa linguagem simples e compreensível, os clientes sejam esclarecidos e informados sobre as diferentes possibilidades de tratamento existentes e disponíveis naquele serviço e/ou em outros serviços, seus diferentes benefícios terapêuticos, seus riscos, vantagens e desvantagens, implicações, envolvimentos e responsabilidades, de modo a que como sujeitos, como pessoas, livremente, possam pensar, refletir, ponderar e, autonomamente, sem pressões ou coação, decidir o que desejam para si, reconhecendo em si sua condição humana, sua condição de gente, responsável e participante direto nas questões que, acredita-se, mais do que para qualquer outra pessoa, a si dizem respeito.

No entanto, poderia se perguntar: quantos clientes, antes de iniciarem uma determinada terapia renal substitutiva, tiveram conhecimento das alternativas terapêuticas, da possibilidade de aderir a outros diferentes tratamentos dialíticos? A este desafio ora apresentado, poderia se contrapor o argumento de que os clientes, ao chegarem a um serviço de hemodiálise, por exemplo, já possam vir com seu acesso venoso e fístula prontos, não cabendo à enfermeira interferir nesta decisão já tomada pelo médico e/ou pela equipe médica com diferentes possibilidades ou não de participação dos clientes envolvidos.

Por outro lado, a partir da nossa condição de seres racionais que só podem pensar sua condição de sujeitos dotados de uma vontade fruto da razão, a partir do uso da sua liberdade, poderia perguntar acerca do livre uso das nossas possibilidades de diferentes movimentos e ações no sentido de advogar a favor do cliente, do seu esclarecimento e da redução da sua desinformação no que diz respeito a si, às diversas possibilidades existentes de como cuidar de si, de se governar, enfim, da sua decisão de como viver. Quantas vezes nossas opções podem se fazer mais no sentido de advogar contra o cliente, mantendo-nos coniventes e omissos ao estabelecido e dado em relação a ele, reforçando e favorecendo que se mantenha numa situação de desconhecimento, de ignorância, de escuridão e impotência quanto ao que diz respeito a si, à sua saúde e à sua vida, ao modo de se cuidar, sem ampliar suas possibilidades de decidir o que deseja e pretende, racional e autonomamente, para si e para a sua vida?3

\footnotetext{
${ }^{3}$ Ao falar em advogar a favor do cliente, refiro-me à possibilidade do seu esclarecimento, de favorecer e estimular que esta pessoa, como todos nós, neste processo, sejamos mais, avancemos e fortaleçamos a nossa condição de pessoas que participam da construção da história, como sujeitos no mundo e que, portanto, fazem diferença, pois ultrapassam uma possivel situação de objeto e de coisa, destituída de vontade própria, já que apenas deve obedecer, acatar, fazer obedecer e fazer cumprir. Parece interessante destacar que ao se apontar a enfermeira como uma profissional que possa advogar a favor dos direitos do cliente que o fato de assumir este papel não se caracterize como uma atitude paternalista ou de
} 
Focalizar a autonomia, seja como um dos princípios da bioética, seja como o supremo princípio da moralidade (Kant, 1995), leva-nos a perguntar-nos como desejar e esperar que o cliente aja, pergunte, questione, discuta e resista frente ao que the é apresentado como decidido e inquestionável se, freqüentemente, desconhece que o que lhe é apresentado como uma verdade e uma certeza pode, no entanto, ser apenas uma das verdades e somente uma possibilidade de certeza? Como esperar que os clientes participem e se envolvam nas decisões que, fundamentalmente, Ihes dizem respeito, tendo que enfrentar, como freqüência, quem representa o poder nas instituições de saúde, quando tais relações se encontram tão permeadas por desigualdades, provavelmente, desnecessárias e inadmissíveis de saber? Um saber que se refere não apenas à doença em si, mas, antes, saber como cuidar de si, como ser cidadão numa sociedade com tamanhas desigualdades; conhecer seus direitos, conhecer que tem direitos, saber que pode perguntar, desconfiar, não saber, recusar ou aceitar.

Uma outra questão a ser abordada, a o focalizar-se a assistência ao ser com uma doença crônica, refere-se à adesão ou não dos clientes ao tratamento proposto. Comumente, seus insucessos nesta adesão são entendidos, reconhecidos e valorizados como insucessos da equipe de saúde e/ou de enfermagem. É possível assim pensar. No entanto, estabelecer laços morais entre o profissional que cuida e quem é cuidado, de modo a que êxitos e "pecados" possam ser intercambiados entre quem orienta como se cuidar e quem se encontra no papel de aprendiz (Foucault, 1990), pode significar retirar e negar, de quem é ensinado e orientado, o seu espaço de liberdade que o capacita a optar e decidir por agir, também, diferentemente do que the foi apresentado como recomendável. Insucesso do serviço e da equipe de saúde? Insucesso da enfermeira que o orientou? Depende dos objetivos a que nos propomos alcançar.

Reconhecer a enfermagem como uma profissão da saúde significa, a meu ver, o reconhecimento do compromisso das profissionais, que a exercem, com o cliente no sentido de Ihes oferecer, apresentar, colocar à sua disposição, para ser utilizado, o seu saber e a sua competência, tendo em vista a assistência a lhe ser prestada, responsabilizando-se, então, por esta assistência prestada e implementada. Tal reconhecimento, entretanto, não significa que estas profissionais se entendam como responsáveis pelo cliente e pelas suas opções e decisões, quando este tem condições de responsabilizar-se por si e de decidir, autonomamente, o que deseja para si, como pretende se cuidar, os riscos que pretende correr, as possíveis conseqüências, positivas e negativas, destas escolhas. Reconhecer a nossa responsabilidade em sermos competentes no nosso fazer profissional, na

infantilização do cliente, já que não se entende tal função como o ocupar o lugardasua voz, da sua palavra, do seu direito (e dever?) de se manifestar, mas, antes, este papel de advogado do cliente significa oportunizar que ele tome conhecimento, seja informado, e compreenda que é possivel, mais, que usarsua voz e sua palavra é um direito seu como cidadão. Parece grotesco, em uma sociedade, a necessidade de se afirmar que o uso da palavra, do diálogo, do questionamento, constituem-se em um direito do cliente como cidadão e, mais ainda, tal informação ser reconhecida como um movimento no sentido de advogar a favor dos clientes. 
assistência prestada, em suas múltiplas dimensões, não significa reconhecer-se como responsável pelas decisões dos clientes, mas a compreensão dos nossos limites de atuação frente ao cliente como um outro, que está fora de nós e que tem o direito de fazer escolhas diferentes das que reconhecemos, talvez, como as melhores e mais adequadas.

Numa linha semelhante, parece ser comum ao se orientar os clientes em relação ao seu auto-cuidado, Ihes serem apresentadas proibições quanto ao que não devem fazer e recomendações em relação ao que devem seguir numa relação predominantemente prescritiva e pastoral (Foucault, 1990), em que se espera a sua obediência e a sua aceitação das verdades apresentadas. Entretanto, quando se pretende uma relação profissional que reconheça o cliente como uma pessoa com capacidade de pensar e de decidir, apresentar uma lista de proibições, de deveres e obrigações a serem seguidas pode significar negar a sua condição de sujeito. Diferentemente, apresentar, numa linguagem acessível, simples e compreensível, com espaço para expressar as suas incompreensões, os seus questionamentos e medos, o que significa determinada patologia, como os seus hábitos de vida podem ou não agravá-la, como determinados cuidados podem ou não aumentar sua sobrevida, os riscos de complicações presentes e as possíveis conseqüências decorrentes das suas opções de vida, pode representar uma maior instrumentalização do cliente para não apenas cuidar de si, mas, também, reconhecer-se como responsável pelo cuidado de si.

Neste sentido, ainda, podemos defrontar-nos com conflitos éticos em que os clientes desejem optar, voluntariamente, por abandonar o seu tratamento, por exemplo, dialítico, frente às complicações e ao comprometimento generalizado de diferentes funções e domínios, da sua capacidade de se cuidar, da sua qualidade de vida. Este desejo representaria, necessariamente, um estado depressivo ou pode ser uma possibilidade de escolha consciente e autônoma frente à sua situação pessoal, familiar, não só presente, mas, também, futura? Estamos preparados para compreender e respeitar uma decisão que pode ser a expressão do exercício de autonomia de um cliente? Como enfrentar tal dilema ético?

Ainda, podem ser aplicadas medidas entendidas como extraordinárias, como a diálise, em pacientes reconhecidos como terminais. Os profissionais, as vezes, decidem pelos clientes o que entendem ser para eles o melhor. Para Culver (1995, p.148), porém, "diferentes pacientes, em situações médicas idênticas, farão escolhas diferentes: os valores pessoais os direcionam a eleger diferentes caminhos entre a qualidade e a duração de suas vidas. Os seus médicos não podem saber, melhor do que eles, o que eles próprios preferem. À medida que o público se torna cada vez mais ciente de que as escolhas de cuidados médicos estão relacionadas a valores pessoais, ele exige obter mais informação e ter um voto de peso na tomada de decisões".

A participação do cliente ou de seus familiares e representantes, nestas decisões, deve ser entendida como um direito, pois apesar de determinadas decisões poderem ser entendidas como um ato de beneficência enquanto um princípio da bioética - fazer o bem ao outro -, podem representar o desrespeito ao princípio da não-maleficência - não fazer o mal - pelo caráter de adiamento de uma 
morte inevitável, num processo que pode estar permeado por diferentes sofrimentos:físicos, emocionais, existenciais.

Nestas situações, freqüentemente, as enfermeiras referem angústia moral, segundo Starzomski (1998), diante do dilema ético que vivenciam, já que podem discordar ou, no mínimo, ter dúvidas quanto à validade da terapêutica adotada e do possível sofrimento (desnecessário?) vivido pelo cliente.

Então, diante de um dilema ético como o desejo explícito de um cliente de abandonar um tratamento dialítico, por vezes, um cliente jovem, mas com significativo e importante comprometimento da sua qualidade de vida pelas complicações e limitações associadas, ou de um conflito ético frente a um cliente reconhecido como terminal, em que há questionamentos sobre a validade ou não de prosseguir um tratamento, Starzomski (1998), a partir de Mc Donald (1994), apresenta um guia estratégico (não uma receita) para auxiliar a construção de uma decisão ética, propondo: a) - a identificação do problema, dos fatos pertinentes e circunstanciais, das decisões e dos seus participantes, pautando-se em modelos de colaboração e não verticais, com ampliação da equipe de trabalho (inserindo-se, aí, o cliente e sua família); os círculos de ética; as consultas éticas aos comitês de ética e aos consultores de ética; b) - a especificação das alternativas possíveis, declarando as opções cabíveis; c) - o uso de recursos éticos para avaliar as alternativas: - os princípios de bioética; - as normas profissionais, leis e códigos, a política da instituição; - a visão contextualizada do cliente; - os múltiplos julgamentos pessoais; - os procedimentos organizados para consulta ética; d) - a proposta e testagem de possíveis resoluções: - a seleção da melhor alternativa ou resolução; - uma análise sensível e crítica da decisão, num ambiente de cuidado; fazer a escolha como uma regra geral; - por último, responder se sente-se confortável com a decisão tomada, e em caso contrário, analisar o que provoca desconforto e repetir o processo até estar convencido de ter tomado a melhor decisão. O objetivo não é realizar a escolha perfeita, mas uma boa escolha.

A importância do trabalho em equipe, permeado pela comunicação, é bastante enfatizada como relevante tanto para reduzir a angústia moral das enfermeiras, como para assegurar o melhor cuidado possível aos clientes portadores de doenças crônicas. Uma equipe de trabalho, como a de nefrologia, que funcione bem pode ser comparada, conforme Starzomski (1998), a uma banda de jazz em que não haja um líder definido, mas que, em diferentes momentos, diferentes instrumentos poderão ser ouvidos, alguns com maior evidência do que outros. Considera inaceitável que qualquer um que atue na equipe de cuidado de saúde não tenha voz, já que o calar-se a respeito de questões morais poderá não assegurar uma boa qualidade de cuidado aos clientes.

Daí, que nas inúmeras relações sociais e de poder que participamos, o dilema pessoal e profissional, o dilema ético, de calar-se ou de usar a palavra, de omitir-se ou de manifestar-se, de, muitas vezes, romper com o instituído e reconhecido como o normal e o esperado, pode ser a opção pessoal e profissional de se reconhecer como um sujeito ético, podendo se compreender, também, que a relação de resistência, de contra-poder, ou no mínimo, a sua possibilidade, indicam o exercício da liberdade dos sujeitos, mediante a relação do eu consigo 
mesmo, permitindo-se, então, que se fale em ética. (Foucault, 1996). O uso da palavra, a expressão das nossas percepções, dúvidas, questionamentos, pode significar o enfrentamento de um conflito e a ruptura de uma situação de harmonia. Nego e anulo minha condição de sujeito, calando-me e mantendo-me numa situação de passividade? Entretanto, quem pode ser beneficiado ou prejudicado com minha decisão? Quais as implicações profissionais, para outros: clientes, equipe de assistência, instituição, da minha decisão pessoal de aceitar que me anule como pessoa, que rechace minha condição de sujeito? Ainda, assim como podemos negar nossa condição humana, podemos, também, as vezes, rechaçar a condição humana dos clientes, ao lhes negar o saber, a possibilidade do entendimento, da palavra e da argumentação.

Conflitos éticos, também, podem ser vivenciados pelas enfermeiras relacionados à situações de transplante renal. Sabe-se que toda Unidade de Diálise deve estar vinculada a uma Unidade deTransplante Renal com os seus clientes em tratamento dialítico inscritos em lista de espera, mantidos clínica e laboratorialmente preparados para o transplante, excetuando-se aqueles que se manifestarem contrários a este tipo de tratamento ou que apresentem contra-indicações médicas formalizadas.

Um problema que poderia ser apontado refere-se às informações necessárias para que o possível receptor do rim não apenas tenha conhecimento dos riscos inerentes ao procedimento, mas possa, a partir destas informações, pensar e decidir se deseja ou não submeter-se ao transplante e às possíveis implicações decorrentes: os riscos cirúrgicos, as possibilidades de sucesso, o tempo do transplante, os medicamentos imuno-supressores com seus efeitos colaterais. Poderia se questionar como tem se realizado este processo de esclarecimento? Em que momento tem sido realizado? Com quanto tempo de antecedência do procedimento em si? Qual o tempo assegurado para os clientes pensarem? Qual o espaço, preferentemente permeado de horizontalidade, de comunicação e abertura previsto e assegurado para que os clientes possam ser ouvidos, apresentar seus questionamentos, suas dúvidas e temores? Quais os cuidados que têm sido tomados para que este processo de esclarecimento se constitua, realmente, num instrumento de ajuda para uma decisão consciente de consentimento ou não para o recebimento de um rim?

O simples preenchimento do Termo de Consentimento do Receptor de Rim, como uma exigência legal, pode caracterizar-se, apenas, como o cumprimento de uma formalidade que preserve a equipe e a instituição hospitalar de possíveis questionamentos legais e deve representar, no entanto, um espaço para o fornecimento de esclarecimentos, informações e que favoreça o processo de uma tomada de decisão autônoma do doente renal (permeada pelo saber, pela liberdade, pelo tempo para pensar e expressar a vontade racional).

Contraditoriamente, apesar dos possíveis riscos relacionados ao transplante renal e à necessidade da decisão e consentimento livre e informado do cliente para sua efetivação, poderia pontuar-se, também, alguns elementos referentes ao custo financeiro coberto pelo Estado - por todos nós - da manutenção de um cliente em tratamento dialítico frente ao custo financeiro da realização de um transplante renal. 
Este probiema ético relaciona-se à justiça como princípio da bioética.

Parece relevante, então, destacar os princípios da Teoria da Justiça de Raw/s (1990, p.33), ou seja "toda pessoa tem igual direito a um regime plenamente suficiente de liberdades básicas iguais, que seja compatível com um regime similar de liberdade para todos" e "as desigualdades sociais e econômicas precisam satisfazer duas condições. Primeiro, devem estar associadas a cargos e posições abertos a todos em condições de uma eqüitativa igualdade de oportunidades e, segundo, devem procurar o máximo benefício dos membros menos avantajados da sociedade". Não basta, portanto, quando se trata da justiça na distribuição de bens e benefícios sociais que ela se faça eqüitativamente, já que são muitas as nossas desigualdades sociais e econômicas, não sendo eqüitativas, também, a igualdade de oportunidades. Serájusto tratar igualmente os desiguais? Será justo que o dinheiro público seja aplicado eqüitativamente para pessoas em situação tão desigual social e economicamente? Contraditoriamente, quem são as pessoas - os clientes -, na nossa sociedade, que têm mais fácil acesso aos serviços de saúde, especialmente, aqueles serviços reconhecidos como mais escassos e com maiores dificuldades de acesso e oferta? Será justo beneficiar igualmente os membros da sociedade que podem se encontrar tão diferentemente na escala social e com possibilidades tão diferenciadas de acesso aos serviços e cuidados de saúde?

Ainda, as instituições de saúde e os profissionais devem garantir a privacidade e o sigilo do doador e do receptor. Em transplantes feitos por doação cadavérica, por vezes, há a manifestação do desejo do receptor conhecer a família do doador. Nesta situação, que representa um dilema ético, novamente, estão presentes normas, procedimentos legais e institucionais, há o envolvimento de pessoas, com diferentes valores, histórias de vida, assim como a identidade de um cliente morto, o que requer, então, não uma simples resposta ou decisão, mas fazse necessária a construção de uma decisão ética.

Em relação à doação intervivos, de modo semelhante ao do receptor, cabe à equipe de saúde buscar o consentimento do doador, de modo a que autorize à equipe médica e à instituição a realizarem os procedimentos necessários para a doação gratuita e confirme sua informação acerca do desconforto e dos riscos decorrentes dos procedimentos de avaliação e cirúrgicos. Por outro lado, faz-se necessário que, como possíveis advogados dos direitos dos clientes, tanto dos possíveis receptores como dos possíveis doadores, estes sejam informados do possível significado da doação de um rim. Esta questão faz-se mais premente no caso de familiares de doentes renais cuja doença básica é desconhecida e que, portanto, apesar de ora hígidos, podem correr um risco ainda maior de virem a ter, no futuro, sua função renal comprometida.

Novamente, deve haver a preocupação com a construção de um espaço sigiloso para que estes possíveis doadores sejam ouvidos, expressem suas dúvidas, desejo ou não de doar, temores, possíveis pressões e coações que venham sofrendo no seu espaço privado, instrumentalizando-se para a sua decisão. Daí, a necessidade do sigilo e da confidência da recusa de um doador, dos motivos por ele apontados, da detecção do seu desejo de não ser doador, já que o possível 
receptor pode não ter a capacidade e a magnitude de compreender e aceitar uma negativa por parte de quem lhe poderia ceder o órgão que necessita. Há que considerar que, além da doação de um rim não se poder fazer de modo compulsório, o doente renal dispõe do tratamento dialítico, além de estar inscrito em uma lista de espera.

Para finalizar, tendo reconhecido que algumas das ponderações feitas vinculam-se, de modo explícito ou não, às diferentes forças presentes nas relações sociais em que estamos, permanentemente, imersos, é importante reforçar, como já referido anteriormente, que a possibilidade do exercício da resistência indica a prática da liberdade dos sujeitos, mediante a relação que, por primeiro, estabelece consigo mesmo, o que permite, então, que se fale em ética (Foucault, 1996). Aliado a isto, parece relevante destacar que, neste jogo de forças e de poder, as normas, as prescrições legais, as determinações com força legal podem, ou melhor, devem ser utilizadas por nós, enfermeiras, como instrumento de força argumentativa de modo a assegurar a qualidade de assistência que, discursivamente, temos afirmado e reafirmado que pretendemos alcançar.

Destaco, então, o que determinam a Lei 7498/86 e o Decreto 94406/87 que dispõem sobre o exercício da enfermagem, em relação à assistência aos pacientes graves somente poder ser realizada por enfermeiros e técnicos de enfermagem. Sabe-se que em muitos dos serviços de hemodiálise, a assistência não vem sendo prestada por técnicos de enfermagem e, talvez, em alguns locais, nem por auxiliares de enfermagem. Qual tem sido, então, a nossa posição frente às administrações das instituições de saúde como enfermeiras responsáveis pelo serviço? Se há denúncia de que existe um efetivo de técnicos de enfermagem disponíveis para serem contratados, os quais não vêm recebendo o espaço necessário na equipe de enfermagem (Informativo COREN, 1998), até que ponto não podemos estar sendo duplamente omissos frente a esta situação, que, porventura, podemos estar enfrentando? Como temos nos articulado, como sujeitos éticos das nossas ações, para enfrentarmos as diferentes situações que vivenciamos de aparente descaso com a segurança dos clientes? Como temos nos aliado aos nossos órgãos de classe na tentativa de mudança de uma realidade em busca da melhoria da qualidade e da segurança da assistência prestada aos nossos clientes? Quais os percursos que temos tentado construir no sentido de concretizar os nossos desejos e assegurar uma assistência que, também, gostaríamos de receber, mas que, antes de tudo, precisamos, temos o dever de oferecer como profissionais comprometidos com os clientes e com a assistência que nos responsabilizamos em oferecer?

Por último e na mesma linha de raciocínio, aponto a portaria 2042/96 do Ministério da Saúde que se refere ao regulamento técnico para o funcionamento dos serviços de terapia substitutiva. Quantos dos enfermeiros que atuam nestes serviços têm conhecimento do seu teor? Quantos dos enfermeiros a têm utilizado como recurso para a negociação de melhores condições de trabalho e organizacionais dos seus locais de trabalho?

Concluo, afirmando que como sujeitos da história, a todo momento, somos instigados a pensar, ponderar e decidir a melhor forma de agir. Acredito que, 
preferentemente, tais decisões deveriam decorrer de processos coletivos em que, pela força do diálogo e da argumentação, se encontre o melhor caminho para percorrer. Frente aos conflitos éticos, do mesmo modo, a construção de uma decisão ética que emerja do trabalho em equipe, certamente, é aquela que será a melhor, pois, possivelmente, esteja envolvendo não apenas a uma pessoa mas o grupo como um todo. Ainda, gostaria de reforçar que respeitar o outro e a sua liberdade de concordar ou de divergir das posições do profissional não deve ser entendido como uma diminuição do compromisso de quem exerce a enfermagem com a sociedade. Antes, reconhecer os limites da atuação profissional frente às possibilidades de cuidado de si dos sujeitos, antes de significar uma manifestação de conformismo com o que aí está, representa o reconhecimento dos cliente como um sujeito da história e da sua história pessoal.

\section{REFERÊNCIASBIBLIOGRÁFICAS:}

1. BELLINO, F. Fundamentos da bioética. Bauru: EDUSC, 1997.

2. COHEN, C.; SEGRE, M. Definição de valores, moral, eticidade e ética. In: SEGRE, M.;COHEN, C. Bioética. São Paulo: EDUSP, 1995.p.13-22.

3. CULVER, C. Casos possíveis de questionamento ético. In: SEGRE, M.;COHEN, C. Bioética. São Paulo: EDUSP, 1995. P. 147- 157.

4. FOUCAULT, M. História da sexualidade II. O uso dos prazeres. Rio de Janeiro: Graal, 1984.

5. ___ Tecnologias del yo, Y otros textos afines. Barcelona: Paidós Ibérica, 1990.

6. Hermenéutica del sujeto. La Plata: Altamira, 1996.

7. INFORMATIVO COREN. Porto Alegre, v. 3, ago. 1998.

8. KANT, I. Fundamentação da metafísica dos costumes. Lisboa:Edições 70, 1995.

9.LUNA, F., SALLES, A. Decisiones de vida y muerte: eutanasia, aborto y otros temas de ética médica. Buenos Aires: Sudamericana, 1995.

10. MINISTÉRIO DA SAÚDE. Portaria 2042/96. Estabelece o regulamento técnico para funcionamento dos serviços de terapia renal substitutiva.

11. RAWLS, J. Sobre las liberdades. Barcelona: Paidós, 1990.

12.STARZOMSKI, R. Ethical issues in nephrology nursing. In:AMERICANNEFROLOGY NURSE'S ASSOTIATION. Contemporarynefrologynursing. New Jersey: Janel Parker, 1998. 